\title{
PESQUISA-FORMAÇÃO COM PROFESSORAS DE CIÊNCIAS E BIOLOGIA DESDE UMA ABORDAGEM (AUTO)BIOGRÁFICA
}

\author{
Research-training with Science and Biology Women Teachers from an \\ (Auto)biographical Approach
}

\author{
Gustavo Lopes Ferreira ${ }^{1}$ \\ Maria Luiza de Araújo Gastal ${ }^{2}$
}

\begin{abstract}
Resumo: $\mathrm{O}$ artigo apresenta uma pesquisa-formação na qual buscamos traçar as contribuições dos Institutos Federais para a formação de professores de Ciências e Biologia, procurando responder: o que professoras, egressas da Licenciatura em Ciências Biológicas de um Instituto do Centro-Oeste brasileiro revelam, narrativamente, de contribuição desse contexto de formação para seu desenvolvimento pessoal e profissional? O interesse está nos sentidos atribuídos às narrativas pelas professoras quando pensam-narram-escutam-editam coletivamente seus processos formativos, durante um dispositivo de pesquisa-formação. Tendo como base os aportes teórico-metodológicos da abordagem (auto)biográfica relatamos, na primeira história do artigo, o dispositivo de pesquisa-formação, que foi o momento em que as professoras narraram-escutaram-editaram narrativas autobiográficas sobre suas histórias de vida e profissional. Na segunda história, realizamos um exercício interpretativo das narrativas a partir de uma análise paradigmática, o que fez emergir três temas que nos forneceram uma leitura do social no individual, estabelecendo elos entre as histórias individuais e os aspectos sócio-históricos. Refletimos que o Instituto Federal possibilitou que essas mulheres pudessem se formar como docentes sem necessitar se deslocar aos centros urbanos ou mesmo realizar uma formação à distância. Elas têm retornado às salas de aula da educação básica os conhecimentos adquiridos na formação inicial e continuada. O trabalho com narrativas docentes pode se constituir em propostas de formação em uma perspectiva biográfico-narrativa, conferindo valor de conhecimento às subjetividades e aos saberes experienciais, trazidos à tona por um exercício de reflexão sobre as experiências docentes.
\end{abstract}

Palavras-chave: Abordagem (auto)biográfica. Formação docente. Instituto Federal de Educação, Ciência e Tecnologia.

Abstract: This article presents a research-training in which we tried to understand the contributions of the Federal Institutes to the training process of Science and Biology teachers

\footnotetext{
${ }^{1}$ Doutor em Educação em Ciências pelo PPGEduC/UnB. Professor do Instituto Federal de Educação, Ciência e Tecnologia Goiano - campus Ceres. Atua na Licenciatura em Ciências Biológicas e no Ensino Médio. Participa do grupo de pesquisa "Tecituras entre Educação em Ciências, Narrativas e Culturas". Orcid: https://orcid.org/0000-0002-4385-2962; E-mail: gustavolofer@gmail.com

${ }^{2}$ Doutora em Ecologia pela Universidade de Brasília. Professora aposentada do Núcleo de Educação Científica do Instituto de Ciências Biológicas - NECBIO/UnB. Atua no Programa de Pós-graduação em Educação em Ciências. Líder do grupo de pesquisa "Tecituras entre Educação em Ciências, Narrativas e Culturas". Orcid: https://orcid.org/0000-0002-1686-8475; E-mail: malugastal@gmail.com
} 
by trying to answer: What do the teachers graduated from the teacher-training course in Biological Sciences at a Federal Institute in the Midwest of Brazil reveal narratively as contributions from the training context to their personal and professional development? The interest is on the meanings given to the narratives made by the teachers when they think-narratelisten-edit collectively their training process during a research-training device. By using the theoretical-methodological contributions of the (auto)biographical approach we described in the first story of the article the research-training device, in which the teachers narrated-listenededited their autobiographical narratives about their life and professional histories. In the second story, we carried out an interpretative exercise of the narratives from a paradigmatic analysis, emerging three themes, of which allowed us to read the social in the individual, by establishing links between the histories and the social-historical aspects. We concluded that The Federal Institute allowed those women to graduate as teachers without the necessity of moving to urban centers or even to attend distance learning. They have taken to basic education classrooms all the knowledge they acquired during their initial and continued training. The work with the teachers' narratives can be formed with training proposals in a biographical-narrative perspective, by giving value of knowledge to the subjectivities and experiential learning which were brought up for a reflection exercise on teachers' experiences.

Keywords: (Auto)biographical approach. Teacher training. Federal Institute of Education, Science and Technology.

\section{Formar e pesquisar professores biográfico-narrativamente}

Como discutir a formação de professores diante de uma profusão de enunciados e propostas dirigidas ao tema? Como encontrar em meio a um excesso de discursos em torno dos professores e de seus papéis na sociedade, nos dizeres de Nóvoa (1999), espaços para o ainda não dito ou pensado? Quanto à formação docente, por vezes, é como se sentíssemos que "não há espaços em branco entre as linhas, ou os espaços em branco já foram ocupados pelos comentários. Não há ocos entre as palavras e as letras" (LARROSA, 2003, p. 53).

Em nossa tese de doutorado ${ }^{3}$, desenvolvida no âmbito de um Programa de Pósgraduação em Educação em Ciências, nos dedicamos a investigar a formação de professores de Ciências e Biologia, procurando por esses espaços em branco de que nos fala Larrosa (2003). Ao longo do estudo, fomos percebendo que ainda há muitas coisas a serem articuladas, que "as respostas não saturam as perguntas" (LARROSA, 2003, p. 55). Zeichner (2009) comenta que uma vertente ainda pouco explorada da formação de professores é sobre como a vivência da formação inicial influencia os docentes e suas aprendizagens.

E partindo dessa questão, encontramos um espaço a ser preenchido: o que seria a formação do ponto de vista do aprendente? Ou, nas palavras de Josso (2010, p. 27), "do ponto de vista daquele que aprende e seu processo de aprendizagem". Para respondê-la realizamos uma pesquisa-formação. Embasados na proposta de Passeggi e Souza (2017), adotamos uma metodologia interativa que tornou inseparável o processo de investigação e de formação, o que ocorreu quando constituímos um grupo de trabalho reflexivo ou biográfico (GT) com professoras de Ciências e Biologia. Ainda na pesquisa-formação proposta, concebemos os envolvidos - docentes participantes e pesquisadores - como seres aprendentes, que refletem sobre suas aprendizagens ao longo da vida.

\footnotetext{
${ }^{3}$ Pesquisa aprovada pelo Comitê de Ética em Pesquisa, CAAE: 79292117.6.0000.0036, Parecer nº 2.482.812.
} 
Sabemos que a formação do professor está envolta por aspectos profissionais e pessoais, por isso, tem início "desde os primórdios de sua escolarização e até mesmo antes - e, depois destes momentos, tem prosseguimento durante todo o percurso profissional do docente" (BUENO, 2002, p. 22). Portanto, os professores em formação inicial já possuem uma série de vivências e aprendizagens, enquanto sujeitos adultos inseridos em contextos sociais e formativos como família, escola e trabalho. Consequentemente, os conhecimentos adquiridos pelos adultos resultam dessa intrincada rede. É neste sentido que em nossa pesquisa incluímos a pessoa em formação, estimulando-a a produzir saberes advindos de suas experiências vividas tanto em espaços formais quanto não-formais e informais de educação (PASSEGGI; SOUZA, 2017).

Refletindo com Nóvoa (2007, p. 16), "a formação dos professores continua hoje muito prisioneira de modelos tradicionais, de modelos teóricos muito formais, que dão pouca importância à prática e à sua reflexão". Opondo-se a tal modelo, o professor-pesquisador espanhol António Bolívar (2002a) propõe a abordagem biográfico-narrativa como uma forma de se romper com essa racionalidade instrumental e tecnológica, segundo a qual o ensino é compreendido como um meio para conseguir determinados resultados. Para o autor,

\footnotetext{
a narratividade se dirige à natureza contextual, específica e complexa dos processos educativos, importando o juízo do professor neste processo, que sempre inclui, além dos aspectos técnicos, dimensões morais, emocionais e políticas (BOLÍVAR, 2002a, p. 7, tradução nossa).
}

Ao longo da investigação, pesquisamos e praticamos a formação docente, valorizando a pessoa do professor e sua história de vida, daí nosso diálogo com António Nóvoa (2013), educador que tem defendido a necessidade da formação se centrar na pessoa e dentro da profissão professor. Ainda nos unimos a Bolívar (2002b) que, a partir de metodologias (auto)biográficas, têm entendido os professores como sujeitos de sua formação, e afirmado que a formação necessita se ancorar nas próprias trajetórias de vida e carreiras profissionais, ou seja, na prática cotidiana docente. Desse modo, na pesquisa-formação empreendida por nós, buscamos compreender as professoras como sujeitos históricos, enquanto detentoras de aprendizagens que veem à consciência por meio da reflexividade autobiográfica, ou seja, frente às narrativas de suas histórias de vida (PASSEGGI; SOUZA, 2017).

O interesse pela formação de professores surgiu durante a prática docente do primeiro autor deste texto, desenvolvida em uma Licenciatura em Ciências Biológicas de um Instituto Federal de Educação, Ciência e Tecnologia (IF), localizado na região Centro-Oeste brasileira. Os IFs foram instituídos no ano de 2008, portanto, possuem apenas treze anos de existência, logo, "o tema dos institutos federais, na sua forma atual, é muito recente para resultados de pesquisa" (CIAVATTA, 2010). Ainda são poucas as pesquisas sobre a formação docente no âmbito da Rede Federal de Educação, Profissional, Científica e Tecnológica (RFEPCT), assim, justifica-se a relevância intelectual do estudo realizado.

Realizamos uma pesquisa-formação atravessada por elementos da abordagem (auto)biográfica, e por esse motivo, adotamos as narrativas autobiográficas enquanto fonte e método de estudo. Fomos ao encontro de sete professoras, ex-estudantes da Licenciatura em Ciências Biológicas do campus Ceres do IF Goiano, buscando perceber como elas constroem sentidos para suas experiências, particularmente as vividas no curso de formação inicial.

As narrativas autobiográficas das docentes foram produzidas de modo individual e coletivamente, no interior de um grupo de trabalho (GT) no qual desenvolvemos o dispositivo 
de pesquisa-formação. Dessa maneira, as narrativas tornaram-se porta de entrada para compreendermos se e como os sentidos das histórias de vida revelaram aprendizagens construídas durante a formação inicial no IF Goiano - campus Ceres.

As narrativas autobiográficas representam as histórias de vida, e denotam que os modos como os indivíduos se formam e o que aprendem são múltiplos e variam sócio-historicamente. Compreender o contexto sócio-histórico, por meio da leitura das histórias individuais das professoras, foi um desafio assumido ao longo da pesquisa-formação e também neste texto. Conferimos valor de conhecimento às subjetividades, como propõe Ferrarotti (2010), entendendo que uma biografia marca a inserção do sujeito no conjunto das relações sociais, assim:

[...] nosso sistema social encontra-se integralmente em cada um dos nossos atos, em cada um dos nossos sonhos, delírios, obras, comportamentos. E a história desse sistema está contida por inteiro na história da nossa vida individual (FERRAROTTI, 2010, p. 44).

De maneira geral, a proposta deste texto é apresentarmos como a pesquisa-formação nos permitiu traçar as contribuições dos IFs para a formação de professores de Ciências e Biologia. Assim, ao longo do artigo procuramos responder o que as professoras, egressas da Licenciatura em Ciências Biológicas revelam, narrativamente, de contribuição do contexto da formação inicial para seu desenvolvimento pessoal e profissional? Logo, nosso interesse recai sobre os sentidos atribuídos às narrativas pelas professoras quando pensam-narram-escutam-editam coletivamente seus processos formativos, durante um dispositivo de pesquisa-formação.

O artigo está constituído por duas histórias interconectadas. A primeira remonta aos aspectos mais importantes do dispositivo de pesquisa-formação, o qual trouxe à tona as narrativas autobiográficas. A segunda alude às narrativas em si, produzidas pelas docentes no dispositivo, e neste momento, nos dedicamos a interpretar as histórias de vida perfazendo uma análise paradigmática, conforme sugere Bolívar (2002a). Mas, antes nos deteremos, brevemente, na metodologia adotada em nossa tese.

\section{A abordagem (auto)biográfica como metodologia}

A abordagem (auto)biográfica está alicerçada no paradigma qualitativo de pesquisa, ao pautar-se nas relações e nas singularidades da experiência humana, bem como na produção de conhecimentos a partir dos significados atribuídos aos assuntos humanos (motivações, sentimentos, desejos e propósitos) (BOLÍVAR, 2014).

Metodologicamente, a abordagem (auto)biográfica dá conta da "materialidade dinâmica do sujeito, suas dimensões pessoais (afetivas, emocionais, biográficas), que somente podem expressar-se por narrativas biográficas nas Ciências Sociais" (BOLÍVAR, 2002a, p. 5, tradução nossa). Por isso, o foco incide nas histórias de vida docentes, ultrapassando a concepção redutora de que as narrativas são meros instrumentos de construção de dados e passando a compreendê-las como princípio ontológico, como construtoras da realidade.

As biografias se destacaram na emergência do " "giro hermenêutico' produzido nos anos de 1970 nas ciências sociais" (BOLÍVAR, 2002a, p. 4, tradução nossa), tornando-se “instrumentos heurísticos tão revolucionários quanto o próprio 'giro autobiográfico', subjetivo, 
interpretativo, qualitativo e alheio aos esquemas de 'hipótese-verificação' da perspectiva positivista" (PASSEGGI; SOUZA, 2017, p. 12).

Nos termos de Bolívar (2002a), as investigações biográficas contrapõem-se às tradicionais-positivistas por estarem assentadas na racionalidade narrativa. Tal racionalidade fundamenta-se na capacidade humana de atribuir significados ao que vai lhe acontecendo. São esses significados que interessam quando se trata de narrativas autobiográficas, principais objetos de estudo da abordagem (auto)biográfica (PASSEGGI, 2015). As formas como as significações são produzidas pelos sujeitos vêm dessa intensa implicação entre as subjetividades e o contexto sócio-histórico.

Somando-se ao exposto acima, Ferrarotti (2010) destaca as três marcas do método biográfico que constituíram nossa pesquisa-formação e, consequentemente, este texto: a possibilidade de leitura da realidade social a partir do ponto de vista de um indivíduo historicamente determinado; a adoção de materiais autobiográficos (narrativas, relatos orais) e o fato de que as narrativas possuem o componente de uma interação pessoal, complexificando a relação estabelecida entre pesquisadores-pesquisados.

Empregamos o termo abordagem (auto)biográfica grafando a palavra "auto" entre parênteses por influência das duas principais obras em torno do tema no Brasil: Vidas de professores (2013) e O método (auto)biográfico e a formação (2010), ambas assinadas por Nóvoa e colaboradores.

Passeggi e Souza (2017, p. 16) interpretam o termo "auto" entre parênteses, dizendo que isso quer "sugerir fontes biográficas e autobiográficas; sinalizar a partilha entre a pessoa que narra e o pesquisador que a escuta". Para nós, o uso dos parênteses ainda ressalta que as narrativas são construídas, ao mesmo tempo, por um trabalho individual e coletivo, sublinhando o caráter intersubjetivo, de cruzamento entre a auto e a heterobiografia. Este termo refere-se "a forma de escrita de si que praticamos quando nos confrontamos com a narrativa alheia" (DELORY-MOMBERGER, 2009, p. 63, tradução nossa).

Nóvoa (2013) categorizou a pluralidade de abordagens (auto)biográficas: a) trabalhos de cunho mais teórico que visam em primeiro plano a investigação; b) estudos práticos seriam voltados à formação e; c) propostas (auto)biográficas de objetivos emancipatórios relacionados à investigação-formação. É com este último grupo que nos identificamos.

Sob uma perspectiva emancipatória e participativa, desenvolvemos o dispositivo de pesquisa-formação junto ao GT das professoras. O dispositivo foi o lugar-tempo para compreendermos o processo formativo das licenciadas-egressas da licenciatura estudada, tendo por base as suas narrativas autobiográficas. As docentes, ao se inserirem em um coletivo e terem contato umas com as outras, fizeram emergir alguns sentidos para suas histórias de vida. A construção desses sentidos se deu ao tomarem consciência de que fazem parte do grupo social e profissional docente, que possuem aprendizagens tecidas em suas próprias experiências de vida e ao longo de seus percursos formativos formais, informais e não-formais.

\section{Do dispositivo de pesquisa-formação}

Pusemos em movimento o dispositivo de pesquisa-formação em sete encontros, que aconteceram de forma presencial e tiveram duração aproximada de duas horas cada, em uma sala de aula do campus Ceres do IF Goiano, entre os meses de maio e novembro do ano de 2018. O número de sete professoras participantes se manteve constante a partir do segundo encontro. 
A articulação entre investigação e formação foi fortemente inspirada no trabalho de Suárez (2010, 2018), percorrendo os seguintes procedimentos: a) produção de narrativas orais e escritas; b) partilha e a edição entre pares dessas narrativas; e c) implicação do pesquisador com o processo, fazendo a mediação e os questionamentos advindos do ouvir/ler as narrativas. Acrescentamos também o aspecto formativo que se deu pela possibilidade de as participantes tomarem para si a responsabilidade sobre sua formação e o compromisso em levarem adiante os projetos pessoais e profissionais percebidos ao longo do dispositivo.

Durante o dispositivo, ainda nos aproximamos da proposta de Josso (2010). Por essa razão tomamos a atitude reflexiva como força motriz para a pesquisa-formação, que para essa autora, se desenrola em três grandes dinâmicas:

a) Dinâmica 1 (A formação em questão): nela ocorre a rememoração livre de fatos, acontecimentos, pessoas, lugares, tempos e espaços significativos para a vida e a formação docente. Em nosso GT, essa dinâmica aconteceu nos encontros em que as licenciadas produziram oralmente suas narrativas, as quais serviram de base para as narrativas autobiográficas que foram escritas, sob encomenda e individualmente.

b) Dinâmica 2 (À descoberta da singularidade dos percursos de formação): onde há a construção do percurso de formação e escrita da narrativa, de forma livre. Antecedendo à escrita, tivemos a produção de narrativas orais, conforme descrevemos na dinâmica 1 . Com suas próprias palavras, as professoras construíram histórias tomando suas experiências de vida como substrato. O que ocorreu é que essa escrita, mesmo que tenha sido fruto de um exercício solitário, foi influenciada pela existência do coletivo, trazendo as marcas das inúmeras interações não só entre nós, participantes do GT, mas também do contexto, das pessoas, dos espaços formativos que constituem as docentes.

c) Dinâmica 3 (Dos percursos de formação aos processos de formação): quando ocorre a reflexão sobre o percurso de formação, buscando explicitar os fios condutores ou tematizações que permitem compreender as histórias narradas. Em alguns encontros, os textos escritos pelas professoras foram partilhados e cada uma apresentou o seu ao coletivo ou em pares, para que as demais colocassem questões e/ou sugestões. Nesse processo, foi crucial a exposição das licenciadas no grupo, permitindo a leitura por outras pessoas e a abertura às múltiplas interpretações, pontos de vista e possíveis edições.

Ao longo do dispositivo de pesquisa-formação percorremos as diferentes dinâmicas, e com isso, foram sendo produzidas narrativas orais e escritas, que compuseram os dados narrativos, foco de nossa interpretação neste artigo. O quadro 1 sintetiza os acontecimentos principais dos sete encontros.

Quadro 1 - Síntese dos encontros do GT divididos por data e acontecimentos

\begin{tabular}{ccl}
\hline Encontro & Data & \multicolumn{1}{c}{ Acontecimentos } \\
$1^{\circ}$ & $05 / 05$ & $\begin{array}{l}\text { Apresentação da proposta de pesquisa-formação; celebração do } \\
\text { contrato ético-didático; produção de narrativas orais; encomenda da } \\
\text { escrita da primeira narrativa com o tema "como cheguei até aqui?". }\end{array}$ \\
$2^{\circ}$ & $19 / 05$ & $\begin{array}{l}\text { Apresentação e debate dos conceitos de escuta sensível e edição } \\
\text { solidária; partilha e edição das narrativas escritas "como cheguei até } \\
\text { aqui?" em subgrupos/pares. } \\
\text { Edição das narrativas "como cheguei até aqui?" nos subgrupos; } \\
\text { socialização da vivência no GT. }\end{array}$ \\
\hline
\end{tabular}




\begin{tabular}{ccl}
\hline $4^{\circ}$ & $25 / 08$ & $\begin{array}{l}\text { Produção de narrativas orais sobre as trajetórias no IF Goiano; } \\
\text { encomenda da escrita da segunda narrativa com o tema "minha vida } \\
\text { no IF Goiano". }\end{array}$ \\
$5^{\circ}$ & $29 / 09$ & $\begin{array}{l}\text { Desenvolvimento da atividade "caixa de narrativas" para promover a } \\
\text { leitura cruzada das narrativas "minha vida no IF Goiano". }\end{array}$ \\
$6^{\circ}$ & $10 / 11$ & $\begin{array}{l}\text { Exercício do conceito de momento-charneira; interpretação coletiva } \\
\text { das narrativas produzidas, buscando encontrar esses momentos. }\end{array}$ \\
$7^{\circ}$ & $30 / 11$ & $\begin{array}{l}\text { Realização de um balanço do dispositivo de pesquisa-formação, } \\
\text { levantando os aprendizados advindos do processo; edição coletiva das } \\
\text { narrativas que as professoras julgaram que ainda mereciam edição; } \\
\text { acolhimento de sugestões para divulgar a vivência do GT, diante da } \\
\text { questão "O que faço agora com o que isso me fez?" }\end{array}$ \\
\hline
\end{tabular}

Fonte: Os autores (2021).

Os dados narrativos da investigação podem ser divididos em dois grupos: I) narrativas orais: falas das professoras ao longo dos encontros, gravadas em áudio, totalizando 420 minutos de conversas que foram, posteriormente, transcritas, dando origem a 80 páginas de texto; II) narrativas escritas: narrativas autobiográficas das professoras e suas reescritas em torno de duas temáticas principais, "como cheguei até aqui?" e "minha vida no IF Goiano". Foram produzidas em média três narrativas escritas por docente, o que significa que, pelo menos uma das versões, consistiu em uma reescrita a partir das edições propostas pelo GT. Ao todo, as participantes escreveram 20 narrativas, sendo dez de cada tema.

Desse conjunto extenso de material procedemos à reconstrução das narrativas, procurando traçar respostas ao questionamento posto logo no início deste texto: o que as professoras, revelam, narrativamente, de contribuição do contexto da formação inicial para seu desenvolvimento pessoal e profissional? Bolívar (2002a) colaborou para pensarmos a questão da interpretação das narrativas por meio de uma abordagem (auto)biográfica. O autor identifica que investigações dessa natureza podem adotar ou combinar diferentes modos de análise, a paradigmática e/ou a narrativa. $\mathrm{Na}$ análise paradigmática dos dados narrativos, procede-se por tipologias, taxonomias ou categorias, para se chegar a determinadas generalizações sobre o grupo estudado. $\mathrm{Na}$ análise narrativa propriamente dita, por outro lado, não se busca por elementos comuns, senão elementos singulares que configuram a história. O que se procura é revelar o caráter único de um caso individual e proporcionar uma compreensão de sua particular complexidade idiossincrática, no contexto histórico e social daquela vida.

Para este texto, apresentamos um exercício interpretativo perfazendo uma análise paradigmática, a partir de temas emergentes das narrativas das docentes. Portanto, recorremos a alguns relatos para fins ilustrativos, construindo uma trama que reúne as diferentes histórias de vida em torno de temáticas comuns, nas quais se integram episódios particulares. Os temas remetem às narrativas das professoras e delimitam subconjuntos que conectam aspectos idiossincráticos e o contexto sócio-histórico.

As participantes do estudo assumiram diversos papéis no GT, foram as protagonistas, sem as quais o dispositivo de pesquisa-formação não teria sido possível; em suas narrativas foram, simultaneamente, autoras e personagens das histórias de vida; e, de maneira geral, atuaram como coinvestigadoras e coformadoras. 
Quando falamos que as professoras foram coinvestigadoras não é apenas para evidenciarmos o empenho pessoal em torno da autoinvestigação de suas trajetórias de vida, mas no contexto da nossa própria pesquisa. As docentes intervieram desde o começo, quando aceitaram o convite para os encontros, até o final, quando retornamos a elas o capítulo da tese dedicado à interpretação de suas histórias para que pudessem editá-lo, deixando-as livres para acrescentar, suprimir ou modificar trechos, ou até mesmo fazer sugestões à trama, como participantes da interpretação.

Também percebemos que as licenciadas atuaram como coformadoras umas das outras, à medida que partilhavam suas narrativas no coletivo. Ao narrarem suas histórias iam se reconhecendo pelas semelhanças e se diferenciando pelas nuances individuais dos percursos.

As professoras se graduaram entre os anos de 2016 e 2017, o que significa que, de algum modo, se conheciam, fosse por terem estudado na mesma turma ou por terem convivido nos espaços do curso. Cinco licenciadas, no funcionamento do GT, cursavam uma especialização na área de ensino de ciências no campus Ceres, o que facilitou o andamento dos trabalhos. As outras duas, não estudantes dessa especialização, se empenharam para se integrar o grupo, mesmo que os encontros ocorressem aos sábados, entre $11 \mathrm{~h}$ e $13 \mathrm{~h}$. Encontramos no GT professoras jovens, com idade média de 30 anos, são elas: Bianca, Cheila, Daianny, Edilene, Josiane, Marly e Tiessa ${ }^{4}$.

\section{Da interpretação das narrativas docentes}

A leitura e escuta sensível das narrativas nos aclarou a compreensão de que a subjetividade não encerra e muito menos explica por si só a complexidade das pessoas. As histórias das docentes "são atravessadas pelo social, pelo político, são feitas de representações, crenças coletivas, de discursos alheios, enfim, traduzem a época e a sociedade nas quais foram produzidas" (DELORY-MOMBERGER, 2012, p. 56). Contudo, não se trata de um reflexo puro e simples do social no individual. Nós, sujeitos sociais, agimos ativamente na construção do meio, reapropriando-nos dele das mais variadas formas e expressando-o em nossas subjetividades. Assim, nesta parte do texto, voltamos o olhar a tais reapropriações singulares do contexto social por parte das docentes, buscando demarcar aspectos sócio-históricos nas histórias individuais.

As três tematizações aqui apresentadas surgiram de nosso retorno constante ao material narrativo, oral e escrito, indo em busca de ler o social no individual. Dessa maneira, os temas refletem "fios condutores que produzem uma 'atmosfera', uma tonalidade na narrativa" (JOSSO, 2010, p. 262). Esses temas abrem diálogos dos mais variados, estabelecendo elos entre as histórias configuradas pelas professoras e os aspectos sócio-históricos a que fazem referência. Esses diálogos ainda são uma oportunidade para refletirmos sobre a tese central do nosso estudo: os IFs têm uma contribuição importante a oferecer à formação de professores de Ciências e Biologia em nosso país.

Os temas principais apontam a experiência social vivida pelas docentes em seu meio de vida, nos diferentes espaços de socialização, em seus pertencimentos profissionais e pessoais. Ao todo interpretamos seis temas gerais, cujos títulos surgiram das autobiografias das professoras. Neste artigo daremos destaque a apenas três: o princípio de tudo foi quando eu

\footnotetext{
${ }^{4}$ As professoras autorizaram a divulgação de seus nomes, fazendo-se autoras de suas próprias histórias.
} 
escolhi cursar uma faculdade; casamos e agora os planos eram outros; além de Ciências e Biologia, há de se ensinar de tudo um pouco

\title{
4.1 O princípio de tudo foi quando eu escolhi cursar uma faculdade
}

O ingresso das professoras no ensino superior escancarou uma situação típica de muitos estudantes de cidades do interior do Brasil: a escassez de cursos superiores, especificamente, os presenciais. Essa é uma situação semelhante ao contexto do interior da Amazônia, apresentado por Fraiha-Martins e Gonçalves (2012). Embora nossas personagens sentissem vontade e tivessem a necessidade de prosseguir nos estudos, o contexto local parecia não lhes favorecer. Além da falta de instituições próximas ou na cidade em que habitavam, as professoras se depararam com outros empecilhos como, o histórico educacional familiar e dos amigos e a falta de recursos financeiros. Foi o que contou Josiane, Tiessa e Marly:

\begin{abstract}
Sempre gostei de estudar, entretanto no terceiro ano [ensino médio] me dediquei melhor. Percebi que a realidade financeira da minha família dificultaria meus estudos, minha irmã só tinha concluído o ensino médio e observava que a maioria dos meus colegas mais velhos dos arredores de onde morava não ia para o ensino superior. [...] Meus pais não tinham condições de me manter na cidade e nem de pagar cursinho para mim, então estudava o máximo que conseguia (trecho de uma narrativa escrita por Josiane).

Lembro-me do ensino médio, eu tinha muita preocupação com o meu futuro profissional. Na época, havia poucos cursos na região e não eram acessíveis para eu me ingressar na faculdade (trecho de uma narrativa escrita por Tiessa).
\end{abstract}

Recursos financeiros para cursar uma faculdade não tinha, mas sonhava na possibilidade (trecho de uma narrativa escrita por Marly).

A falta de recursos para custeio do ensino superior é um dos impeditivos para que estudantes tenham acesso a esse nível de ensino, o que se agrava quando percebemos que, conforme o Censo da Educação Superior (2019), 88,2\% das Instituições de Educação Superior (IES) do país são privadas. Isso não é diferente em Ceres e região, onde a maior parte da oferta de educação superior está disponível em instituições particulares de ensino.

A rede privada de ensino ofertou $93,8 \%$ do total de vagas em cursos de graduação no ano de 2018, enquanto a rede pública teve uma participação de $6,2 \%$ no total de vagas oferecidas (BRASIL, 2019). Um número muito baixo para a realidade do nosso país, cuja população, em sua maioria, é pobre. Aproximadamente $60 \%$ dos brasileiros têm rendimento mensal domiciliar de até um salário mínimo, segundo dados do IBGE (2018).

$\mathrm{Na}$ época de escolha pelo curso superior, as professoras foram confrontadas com suas realidades. Estas são marcadas pela falta de condições financeiras para custeio de um curso em uma instituição privada, pela baixa variedade de cursos superiores e de instituições na região de suas moradias. Na Microrregião de Ceres existem duas IES públicas, o IF Goiano e a Universidade Estadual de Goiás (UEG). Adotando o critério de proximidade, as duas unidades de ensino localizadas em Ceres, o IF Goiano e a UEG, seriam as alternativas mais viáveis para nossas professoras, pois as outras duas unidades da IES estadual localizam-se nas cidades de Goianésia e Itapuranga, que estão, respectivamente, a $64 \mathrm{Km}$ e $68 \mathrm{Km}$ de distância de Ceres. Tais distâncias inviabilizariam a mobilidade diária até esses municípios. 
O curso de Licenciatura em Ciências Biológicas no campus Ceres, apesar de ser uma opção ao alcance delas, não foi a primeira alternativa. Fenômeno semelhante ao apontado por Silva (2016), ao estudar os alunos do mencionado curso encontrou que, para quase $60 \%$ deles a Biologia não foi a primeira opção. De modo geral, há um baixo interesse pelas licenciaturas, refletido no Censo da Educação Superior, que mostra que "os cursos de bacharelado continuam concentrando a maioria dos ingressantes da educação superior $(58,0 \%)$, seguidos pelos cursos tecnológicos $(20,9 \%)$ e os de licenciatura (20,5\%)" (BRASIL, 2019, p. 16).

Para as professoras do grupo outras opções se destacaram na frente das Ciências Biológicas: Administração (para Bianca), Pedagogia (para Tiessa e Marly), Comunicação de Rádio e TV (para Daianny), Enfermagem e Licenciatura em Química (para Cheila), Agronomia (para Josiane) e Marketing (para Edilene). Três delas narraram:

A princípio no ensino médio eu tinha me identificado, e hoje eu enxergo que foi mais
por uma questão de afinidade com o professor da disciplina, e não com a disciplina
em si, com a Química. Então eu optei pelo vestibular de Química, aí eu passei. Eu fiz
um ano de Química. Meu Deus como eu sofri (trecho de uma narrativa oral de Cheila).

Fiz o processo seletivo para curso Técnico em Administração no IF e também vestibular para Agronomia no IF. Não fui selecionada para Agronomia, mas passei para Técnico em Administração e nele cheguei até realizar matrícula (trecho de uma narrativa escrita por Josiane).

Sempre gostei de comunicação e tinha o desejo de fazer Comunicação de Rádio e TV, uma vez que trabalhava na locução em uma rádio há três anos. Porém, devido às condições financeiras não serem tão favoráveis e o medo do novo ter falado mais alto, resolvi prestar o vestibular para o curso de licenciatura em Biologia, que era um dos meus favoritos (trecho de uma narrativa escrita por Daianny).

A existência do IF Goiano em Ceres ofereceu condições para que as licenciadas pudessem se profissionalizar em nível superior. Os IFs carregam a política de expansão do ensino superior e da formação de professores em instituições públicas, colaborando para o expressivo aumento do número de matrículas em licenciaturas entre os anos 2008 e 2018 na rede federal, em 89,7\% (BRASIL, 2019).

No IF Goiano as docentes cursaram a formação inicial na modalidade presencial e em uma IES pública, percorrendo um caminho oposto da tendência brasileira que é a de possuir predominância de alunos matriculados em licenciaturas à distância $(50,2 \%)$, em contraposição às matrículas em cursos presenciais (49,8\%) (BRASIL, 2019).

Por meio de sua atuação, o campus do IF Goiano levou à microrregião de Ceres novidades formativas, permitindo aos estudantes com interesses diversos terem acesso ao ensino público e de qualidade, sem precisar se deslocar aos grandes centros urbanos do Brasil. Parece ser o caso das professoras do nosso GT. Elas souberam aproveitar aquilo que a instituição lhes tem oferecido, e até o momento, cursaram a licenciatura e a especialização latu sensu.

Não há como falar de educação superior pública no interior do país, atualmente, sem considerar o expressivo espraiamento dos campi dos IFs, um dos reflexos da política de interiorização do ensino público federal, levada a cabo pela RFEPCT, no ano de 2008. Exemplarmente, em seus 13 campi o IF Goiano oferece à comunidade 53 cursos técnicos, 59 graduações e 23 pós-graduações. Somado a isso, como consta na Plataforma Nilo Peçanha, com 
dados do ano de 2019, existem 812 professores atuantes, sendo 379 doutores, 338 mestres, 55 especialistas e 40 graduados.

\subsection{Casamos e agora os planos eram outros}

As narrativas docentes revelaram a condição das mulheres na sociedade, sobretudo o relacionamento com suas famílias e suas performances sociais de mães, esposas e trabalhadoras. Elas deram a conhecer dramas vividos que emergiram da sua "existência singular-plural" (JOSSO, 2010, p. 69). Para esta autora, uma pessoa procura exprimir sua individualidade diante da coletividade, a qual parece impor-lhe determinadas normas ou regras do jogo, na forma de representações sociais que projetam papeis a serem desempenhados. É como se o coletivo nos enquadrasse em um lugar pré-determinado.

Percebemos o efeito de papeis femininos circulantes em nossa sociedade sobre as professoras do GT. Foi em nome dessas representações que algumas, em diferentes momentos, abdicaram de atuar profissionalmente para se dedicar à família, o que foi visto nas histórias de Edilene, Marly e Tiessa:

Era enorme a minha vontade de cursar um ensino superior, porém nessa altura veio casamento, filhos, o que tornava cada vez mais difícil (trecho de uma narrativa oral de Edilene).

O sonho de Marly em trabalhar e seguir no ensino superior foi reorientado pelo casamento e maternidade, motivos que a fizeram abrir mão, por certo tempo, da atividade profissional na qual havia investido e sonhado, ainda nos tempos do curso de Magistério:

\footnotetext{
Comecei a namorar, conheci um rapaz e me apaixonei, fiquei grávida, e os planos mudaram. Casamos e agora os planos eram outros, filhos, afazeres domésticos, cuidar do esposo (trecho de uma narrativa escrita por Marly).

Eu tive minha filha, e este é o motivo de ainda não estar trabalhando, me dedico inteiramente na arte maternal. Este também é um momento muito especial para minha vida (trecho de uma narrativa oral de Tiessa).
}

Essas três professoras apresentaram em suas histórias, ainda que não explicitamente, a presença do marido e dos filhos, algo notado também por Moita (2013). O meio familiar impactou seus itinerários profissionais e formativos, inclusive a formação inicial no IF Goiano. Marly queixou-se de que, quando começou o curso, além de passar o dia todo fora, no trabalho, precisou deixar sua família também à noite para estudar. Na mesma direção, Cheila teve que se desdobrar para conciliar trabalho, família e estudo.

Lidar com a múltipla jornada foi um aspecto bastante comum compartilhado nas histórias de vida por outras licenciadas. No caso de Cheila, além de morar a $60 \mathrm{Km}$ de distância da faculdade:

Trabalhava durante muito tempo de segunda a sábado de 07:00h às 17:00h, tomava um banho (quando dava tempo) e ia para o ponto para pegar o ônibus e ir para Ceres. Tinha aula até às 22:45h, chegava em casa por volta de 00:00h (trecho de uma narrativa escrita por Cheila). 
Edilene narrou que por um período suportou a rotina dividida entre trabalho e estudo, contudo, pela falta de tempo para se dedicar à graduação e à filha pequena, tomou duas decisões difíceis: abandonou o trabalho em uma loja de motocicletas, passando a viver apenas com a bolsa do Programa de Bolsa de Iniciação à Docência (Pibid) e levou a filha para morar com os avós na fazenda.

Nas histórias de Bianca e de Daianny a entrada na licenciatura também impactou suas trajetórias. Ambas deixaram seus empregos para se dedicar, exclusivamente, ao curso e ao Pibid. A professora Bianca exonerou-se do cargo efetivo no qual atuava na limpeza de uma escola municipal e passou a viver da bolsa de iniciação à docência. Daianny, além da perda salarial, deixou de exercer a atividade de locutora de rádio, pela qual era bastante apaixonada.

Por esses conflitos e ajustes realizados pelas sete professoras em suas rotinas ao tornarem-se licenciandas no IF Goiano, evidenciamos que, "uma trajetória coloca em cena um ser-sujeito relacionado com pessoas, contextos e consigo mesmo numa tensão permanente entre os modelos possíveis de identificação com outrem (conformação) e aspirações à diferenciação (singularização)" (JOSSO, 2010, p. 70).

Fossem quais fossem os conflitos vividos, é certo que, de algum modo, foram sendo superados à medida que as professoras tomaram para si a responsabilidade por suas formações. $E$ isto veio acompanhado da autonomização frente às dificuldades de desempenharem, simultaneamente, múltiplos papeis sociais: de mães, esposas, estudantes, trabalhadoras. Reforçamos que as representações e a imposição de papeis inerentes a essas funções são gestadas em uma sociedade patriarcal.

A busca de autonomização e de responsabilização por suas formações apenas foi possível pelas condições contextuais favoráveis advindas da presença do IF Goiano em Ceres. Pelas narrativas autobiográficas docentes, um dos desdobramentos da política de criação dos IFs é a de encorajar mulheres que, possivelmente, estariam fadadas a desempenhar o papel esperado pela sociedade, ou seja, distantes dos espaços formativos e do mundo do trabalho, e próximas ao modelo idealizado de mulher, dona de casa e dedicada.

\subsection{Além de Ciências e Biologia, há de se ensinar de tudo um pouco}

Podemos refletir sobre como tem sido ser docente de Ciências e Biologia no cotidiano da profissão a partir das histórias de vida de nossas personagens. Muitas delas atuam em escolas da rede estadual de educação de Goiás. Diante da denúncia de Edilene, título deste tópico, revela-se o déficit de professores na rede estadual de ensino, que faz com que muitas tenham que se desdobrar para ministrar disciplinas diferentes de sua área de formação.

Pusemo-nos a pensar: como é o ensino de ciências no interior de Goiás? Tem sido marcado pela falta de professores para disciplinas especializadas. Isso se repete nas escolas básicas da rede pública como problema que assola muitos municípios brasileiros (BRASIL, 2018). No ensino médio, os melhores resultados do indicador de adequação da formação docente foram observados nas disciplinas Biologia, Língua Portuguesa, Educação Física, Matemática, Geografia e História com percentuais acima de 70\% (BRASIL, 2018).

Focalizando as duas disciplinas para as quais as professoras foram habilitadas, Ciências da Natureza tem $61 \%$ e Biologia possui $79,8 \%$ das turmas com professores com formação adequada, ou seja, licenciados ou bacharéis em Ciências Biológicas com formação pedagógica (BRASIL, 2018). No entanto, em âmbito nacional, as Regiões Nordeste e grande parte da 
Região Centro-Oeste, local de atuação de nossas professoras, apresentam menores percentuais de disciplinas ministradas por docentes com formação adequada, tanto nos anos finais do ensino fundamental quanto no ensino médio (BRASIL, 2018). Esse cenário faz com que muitos atuem em disciplinas diferentes da sua formação original, compondo assim uma identidade polivalente.

Nossas personagens, ao assumirem aulas na rede estadual de Goiás, na cidade de Ceres e região, a fim de completar suas cargas horárias precisam ministrar disciplinas para quais não são habilitadas. Foi assim com Bianca, Cheila e Edilene que, além de Ciências e Biologia, ministraram Língua Portuguesa, Filosofia, Sociologia, Artes, Geografia, Matemática, Química. Como bem expôs Edilene, "de tudo um pouco".

De forma propositiva e a partir da realidade narrada, sugerimos duas maneiras que poderiam vir a solucionar ou mitigar a falta de professores sem formação adequada para algumas disciplinas escolares: ampliar o número de vagas de concursos para atender a demanda das escolas públicas e oferecer oportunidades formativas aos professores em cursos superiores de diferentes áreas.

Refletimos sobre a primeira proposta, de efeito mais imediato. No último concurso da então Secretaria de Estado da Educação, Cultura e Esporte (SEDUCE/GO) do ano de 2018, foram oferecidas vagas para docentes apenas para Biologia, Química, Física e Matemática, sendo 42 vagas de Biologia para todo o Estado. Notadamente, este número é insuficiente e não atende a real demanda da rede estadual, composta por 246 municípios e quase 5 mil escolas. Para ilustrarmos, na área da microrregião de Ceres, apenas a cidade de Goianésia recebeu duas vagas para docentes de Biologia (GOIÁS, 2018).

Quanto à segunda proposta, uma saída de médio e longo prazo seria ampliar o investimento na expansão e diversificação da formação de professores em nível superior, como prevê o último Plano Nacional de Educação (PNE) na meta 15 (BRASIL, 2014). Esta lei busca assegurar que "todos os professores e as professoras da educação básica possuam formação específica de nível superior, obtida em curso de licenciatura na área de conhecimento em que atuam" (BRASIL, 2014).

Acreditamos que os IFs são instituições que poderiam incrementar o cenário da formação docente no país, articulando-se e somando esforços com outros espaços universitários. A lei de criação dos institutos (Lei nº 11.892/2008) prevê que essas instituições devem garantir no mínimo $20 \%$ de suas vagas para cursos de licenciatura, programas especiais de formação pedagógica, procurando formar professores para a educação básica, prioritariamente nas áreas de ciências e matemática, e para educação profissional (BRASIL, 2008). Essa meta encontra respaldo no PNE/2014, o qual define como estratégia o fomento à formação de professores para a educação básica, sobretudo nas áreas de ciências e matemática, e o atendimento ao déficit de profissionais em áreas específicas (BRASIL, 2014).

Outra ação dos IFs na formação de professores do país consiste na sua atuação majoritária em regiões interioranas, facilitando o acesso e a formação de futuros docentes em cidades de porte pequeno.

\section{Das reflexões sobre a pesquisa}

O que as professoras participantes sinalizaram, por meio de narrativas autobiográficas, como contribuição do contexto de formação inicial do IF Goiano para seus desenvolvimentos 
profissional e pessoal? De fato, fica evidente que a instituição tem contribuído para levar educação pública aos municípios do interior do país, em decorrência da interiorização, o que tem permitido às docentes experimentarem processos de autonomização sobre suas formações. A interiorização dos IFs é um emblema de uma política educacional que visa democratizar a educação e promover a justiça social.

Outro desdobramento da interiorização, seguindo o disposto na Lei ${ }^{\circ}$ 11.892/2008, quando trata das finalidades e características dos IFs, é a atenção dessas instituições às demandas formativas locais após mapeamento das potencialidades de desenvolvimento socioeconômico e cultural. Assim, o fomento ao ensino de ciências aparece como área prioritária para os IFs, buscando tornarem-se "centros de referência no apoio à oferta do ensino de ciências nas instituições públicas de ensino, oferecendo capacitação técnica e atualização pedagógica aos docentes das redes públicas de ensino" (BRASIL, 2008).

A existência da Licenciatura em Ciências Biológicas e da Especialização na área de ensino de ciências permitiram às egressas a construção de suas identidades docentes. O IF Goiano, ao se atentar às demandas do ensino de ciências da região de Ceres, fez com que essas professoras, nascidas no interior de Goiás, pudessem se graduar em nível superior sem necessitar se deslocar aos centros urbanos ou mesmo realizar uma formação à distância. Elas têm permanecido no interior, ainda que em função de seus vínculos familiares, retornando às salas de aula da educação básica os conhecimentos adquiridos na formação inicial e continuada.

Também como está na lei, os IFs trazem a verticalização ${ }^{5}$ como um de seus objetivos, quando se propõem a "promover a integração e a verticalização da educação básica à educação profissional e educação superior, otimizando a infraestrutura física, os quadros de pessoal e os recursos de gestão" (BRASIL, 2008). Foi assim que, a verticalização da graduação para a pósgraduação latu sensu possibilitou que a formação continuada das professoras viesse a acontecer, fazendo-as assumirem, para além da autonomização, a responsabilidade em dar sequência aos seus desenvolvimentos profissionais. A tomada de consciência de que a formação pertence às próprias professoras, por isso, depende de suas disposições em estarem abertas ao que lhes vai acontecendo, as têm tornado autoras de seus processos formativos. Aceitar essa responsabilidade as tem impulsionado a ir em busca de novas formações, agora na especialização, quem sabe depois no mestrado, quiçá no doutorado.

Ao longo da investigação desenvolvemos o dispositivo de pesquisa-formação estabelecendo elos de confiança com as professoras, os quais foram imprescindíveis para reforçar as contribuições da abordagem (auto)biográfica realizada. Os apontamentos das participantes podem desembocar em propostas de formação inicial e continuada de professores de Ciências e Biologia. Uma delas é a reivindicação de uma prática formativa biográficonarrativa, valorizando a subjetividade, valores, sentimentos, representações e saberes experienciais docentes, trazidos à tona por exercícios constantes de reflexão sobre as experiências vividas.

Quem sabe possamos fabular um modelo de formação inicial mais conectado aos saberes experienciais trazidos pelos adultos. Para tanto, necessitamos rever a lógica das

\footnotetext{
5 Segundo Ferreira (2019, p. 40), a verticalização é "inerente à existência dos IFs, sendo uma marca que os diferencia das universidades, constituindo assim uma nova institucionalidade. [...] É um compromisso com toda a sociedade, que vem sendo praticado por intermédio da oferta de cursos em diferentes níveis, concentrados em eixos tecnológicos específicos".
} 
licenciaturas que parecem tratar os adultos como alunos recém-saídos da educação básica e telas em branco, e não os considera sujeitos dotados de experiências e aprendizagens constituídas no contexto material, na arte, no trabalho, na família, com as pessoas e no confronto entre a individualidade e a coletividade.

\section{Referências}

BOLÍVAR, Antonio. Las historias de vida del profesorado: voces y contextos. Revista mexicana de investigación educativa, v. 19, n. 62, p. 711-734, 2014.

BOLÍVAR, Antonio. “¿De nobis ipsis silemus?”: Epistemología de la investigación biográfico-narrativa en educación. Revista Electrónica de Investigación Educativa, v.1, n. 4, p. 41-62, 2002a.

BOLÍVAR, Antonio. (Org.). Profissão professor: o itinerário profissional e construção da escola. Tradução de Gilson César Cardoso de Sousa. Bauru, SP: EDUSC, 2002b.

BRASIL. Instituto Nacional de Estudos e Pesquisas Educacionais Anísio Teixeira (Inep). Censo da Educação Superior 2018: notas estatísticas. Brasília, 2019. Disponível em: http://download.inep.gov.br/educacao_superior/censo_superior/documentos/2019/censo_da_e ducacao_superior_2018-notas_estatisticas.pdf. Acesso em: 30 mai. 2020.

BRASIL. Instituto Nacional de Estudos e Pesquisas Educacionais Anísio Teixeira (Inep). Censo Escolar 2018: notas estatísticas. Brasília, 2019. Disponível em: http://portal.inep.gov.br/web/guest/resultados-e-resumos. Acesso em: 01 nov. 2020.

BRASIL. Congresso Nacional. Lei $\mathrm{n}^{\circ} 13.005$, de 25 de junho de 2014. Aprova o Plano Nacional de Educação - PNE e dá outras providências. Diário Oficial [da] República Federativa do Brasil, Poder Executivo. Brasília, DF, 26 jun. 2014, Seção 1, p. 1. Disponível em: http://www.planalto.gov.br/ccivil_03/_ato2011-2014/2014/lei/113005.htm. Acesso em: 28 set. 2020.

BRASIL. Congresso Nacional. Lei no 11.892, de 29 de dezembro de 2008. Institui a Rede Federal de Educação Profissional Científica e Tecnológica e dá outras providências. Diário Oficial [da] República Federativa do Brasil, Poder Executivo. Brasília, DF, 30 dez. 2008, Seção 1, p. 1. Disponível em: http://www.planalto.gov.br/ccivil_03/_ato20072010/2008/lei/111892.htm. Acesso em: 29 out. 2020.

BUENO, Belmira Oliveira. O método autobiográfico e os estudos com histórias de vida de professores: a questão da subjetividade. Educação e Pesquisa, v. 28, n. 1, p. 11-30, jan./jun. 2002.

CIAVATTA, Maria. Universidades tecnológicas: horizonte dos Institutos Federais de Educação, Ciência e Tecnologia (IFETS)? In: MOLL, J. e Col. Educação profissional e tecnológica no Brasil contemporâneo - desafios, tensões e possibilidades. Porto Alegre: Artmed, p. 159-174, 2010.

DELORY-MOMBERGER, Christine. Abordagens metodológicas na pesquisa biográfica. Revista Brasileira de Educação, v. 17, n. 51, p. 523-536, set./dez., 2012. 
FERRAROTTI, Franco. Sobre a autonomia do método autobiográfico. In: NÓVOA, A.; FINGER, M. (org.). O método (auto)biográfico e a formação. São Paulo: Paulus, p. 31-58, 2010.

FERREIRA, Ana Cláudia. A nova institucionalidade dos Institutos Federais de Educação, Ciência e Tecnologia: potencialidades e desafios. In: SOBRINHO, S. C.; PLÁCIDO, R. L.; RIBEIRO, E. A. W. (org.). Os "Nós" que fortalecem a Rede Federal de Educação Profissional Científica e Tecnológica: Experiência e expertises nos/dos Institutos Federais IFs. Blumenau: IFC, p. 35-44, 2019.

FRAIHA-MARTINS, France; GONÇALVES, Terezinha Valim Oliver. Experiência formativa mediatizada por ambiente virtual de aprendizagem: formação de professores de Ciências e Matemática na Amazônia. Amazônia - Revista de Educação em Ciências e Matemáticas, v. 8, n. 16 - jan./jun., p.146-158, 2012.

GOIÁS. Edital n⿳002 - SEGPLAN/SEDUCE, de 5 de abril de 2018. [Concurso público para provimento de vagas no cargo de professor nível III]. Goiás, 2018. Disponível em: https://www.escoladegoverno.go.gov.br/images/imagens_migradas/upload/arquivos/201804/edital-retificado-seduce-professores.pdf. Acesso em: 28 set. 2020.

IBGE. Instituto Brasileiro de Geografia e Estatística. 2018. Disponível em: https://cidades.ibge.gov.br/brasil/go/ceres/panorama. Acesso em: 29 out. 2019.

JOSSO, Marie-Christine. Experiências de vida e formação. Natal, RN: EDUFRN, São Paulo: Paulus, 2010.

LARROSA, Jorge. Estudar. Belo Horizonte: Autêntica, 2003.

MOITA, Maria da Conceição. Percursos de formação e de transformação. In: NÓVOA, A. (Org.). Vidas de professores. 2. ed. Portugal: Porto Editora, p. 111-140, 2013.

NÓVOA, António. Vidas de professores. 2. ed. Porto: Porto Ed., 2013.

NÓVOA, António. A formação tem que passar por aqui: as histórias de vida no Projeto Prosalus. In: NÓVOA, A.; FINGER, M. (org.) O método (auto)biográfico e a formação. Natal: EDUFRN; São Paulo: Paulus, p. 155-188, 2010.

NÓVOA, António. Nada substitui um bom professor. São Paulo: SINPRO-SP, 2007. Disponível em: https://www.sinprosp.org.br/arquivos/novoa/livreto_novoa.pdf. Acesso em: 15 abr. 2021.

NÓVOA, António. Os professores na virada do milênio: do excesso dos discursos à pobreza. Educação e Pesquisa, v. 25, n. 1, p. 11-20, 1999. Disponível em:

https://www.scielo.br/pdf/ep/v25n1/v25n1a02.pdf. Acesso em: 15 abr. 2021.

PASSEGGI, Maria da Conceição; SOUZA; Elizeu Clementino. O movimento (auto) biográfico no Brasil: esboço de suas configurações no campo educacional. Investigación Cualitativa, v. 2, n. 1, p. 6-26, 2017. 
PASSEGGI, Maria da Conceição. Narrativa, experiência y reflexión autobiográfica: por una epistemologia del sur en educación. In: ARANGO, G. J. M. (Comp.). Narrativas de experiência en educación y pedagogia de la memória. Ciudad Autónoma de Buenos Aires: Editorial FFyL de la Universidad de Buenos Aires, p. 69-87, 2015.

SECRETARIA DE EDUCAÇÃO PROFISSIONAL E TECNOLÓGICA DO MINISTÉRIO DA EDUCAÇÃO (SETEC/MEC). Plataforma Nilo Peçanha. 2020. Disponível em: https://www.plataformanilopecanha.org/. Acesso em: 07 set. 2020.

SILVA, Tiessa Lorraine Miguel. Uma viagem pelas histórias de licenciandos do Curso de Ciências Biológicas do IF Goiano - campus Ceres. 2016. 56 f. Trabalho de Curso (Licenciatura em Ciências Biológicas) - Instituto Federal de Educação, Ciência e Tecnologia Goiano, Ceres/GO, 2016.

SUÁREZ, Daniel. Narrar la experiencia educativa como formación. La documentación narrativa y el desarrollo profesional de los docentes. In: FURLANETTO, E. C. et al. (org.). Espaços formativos, trajetórias de vida e narrativas docentes. Curitiba: CRV, p. 29-42, 2018.

SUÁREZ, Daniel. La documentación narrativa de experiencias pedagógicas como estrategia de indagación-acción-formación de docentes. In: PASSEGGI, M. C.; SOUZA, E. C. (org.). Memoria docente, investigación y formación. Buenos Aires: Editorial de la Facultad de Filosofía y Letras Universidad de Buenos Aires, p. 131-152, 2010.

ZEICHNER, Kenneth. Uma agenda de pesquisa para a formação docente. Formação Docente - Revista brasileira de Pesquisa sobre Formação Docente, v. 1, n. 1, p. 13-40, ago./dez., 2009. Disponível em:

https://revformacaodocente.com.br/index.php/rbpfp/article/view/3. Acesso em: 28 out. 2018.

Recebido em agosto de 2021.

Aprovado em outubro de 2021. 